\title{
Notas para o Estudo da Mortalidade Infantil Entre a População Escrava no Rio Grande do Sul (1850-1872)
}

Jurema Mazuhy Gertze*

O presente artigo, de caráter exploratório, tem como objetivo contribuir para o resgate da história da criança negra escravizada no Rio Grande do Sul, abordando um dos aspectos mais contundentes do escravismo: a mortalidade.

Interessada no estudo da história da criança em Porto Alegre no século XIX, minha atenção se volta, no que se refere à escravidão no sul do Brasil, justamente para a situação da infância cativa.

Ao mesmo tempo que se constata o quanto ainda há por ser pesquisado acerca da história do escravismo, percebe-se hoje um crescente interesse pelo tema, mas a criança negra continua ausente.

Utilizando uma fonte específica, delimitada e praticamente inédita, os Registros de Óbitos dos Escravos sepultados no cemitério da Santa Casa de Misericórdia de Porto Alegre, pretende-se demonstrar o percentual de crianças entre o total de escravos sepultados no período de 1850 a 1872.

A delimitação tempora não é aleatória. O ano de 1850 marca a fundação do cemitério da Santa Casa bem como o início dos assentamentos dos escravos ali sepultados. Em 21 de setembro de 1871, foi aprovada a Lei Rio Branco ou Lei do Ventre Livre, uma disposição legal que atingiu diretamente as crianças escravizadas. Contudo, pelo fato desta lei ter sido regulamentada somente em 13 de novembro de 1872 , pelo

\footnotetext{
* Mestre em História do Brasil pela PUCRS e historiógrafa do Centro de Documentaçăo e Pesquisa (CEDOP) da Santa Casa de Misericórdia de Porto Alegre.
} 
decreto $\mathrm{n}^{\circ} 5135$, optou-se por estender o levantamento dos registros de óbitos até dezembro daquele ano.

Convém esclarecer desde logo que ao referir a lei não se tem a intenção de analisá-la. Tal procedimento extrapola o objetivo deste trabalho e a menção da mesma deve-se somente à necessidade de buscar uma justificativa para a delimitação temporal.

\section{A criança escravizada no Brasil}

As crianças negras escravizadas refletiam, mais do que os adultos, a ambição lucrativa do comércio de escravos. Ao embarcar num negreiro na costa africana com destino aos portos brasileiros, elas eram freqüentemente excluídas das listas de embarque por serem de pouco valor e de difícil comercialização, já que não eram imediatamente produtivas. ${ }^{1}$

Partilhando com todos os escravos as péssimas condições em que se realizavam as viagens transatlânticas, as crianças sofriam muito mais, devido obviamente à sua maior vulnerabillidade diante das restrições alimentares e das precaríssimas condições de higiene.

Segundo uma descrição de Robert Walsh a respeito do negreiro português Veloz, se pode avaliar esta situação: “[...] ali encontravam-se algumas crianças junto à borda do navio; estavam deitadas em estado de torpor. [...]. As pequenas criaturas pareciam indiferentes tanto à vida como à morte, e quando eram carregadas para o convés muitas não conseguiam ficar de pé [...]."2

As crianças com menos de 8 anos de idade eram denominadas "moleques" e, dos 8 aos 15 anos, "molecões". Para fins de comércio os primeiros equivaliam a $1 / 2$ peça e, portanto, possuíam um menor valor. As que se encontravam ainda em fase de aleitamento não eram sequer contabilizadas. ${ }^{3}$

Uma vez desembarcadas e postas à venda, elas eram negociadas a preços mais baixos, assim como os escravos velhos, os doentes e os incapazes, que chegavam a valer 10 vezes menos do que um escravo adulto no auge de sua capacidade produtiva. ${ }^{4}$

Nascidas ou não no Brasil, a realidade das crianças negras escravizadas era bastante dura. Quando sobreviviam ao nascimento estavam sujeitas a morrerem precocemente, devido ao precário atendimento que recebiam de suas mães. Estas retornavam "ao trabalho [...] num espaço e tempo curto: cerca de três dias". 5 
Por outro lado, parece ter havido um desinteresse por parte dos proprietários de escravos em relação à procriação dos cativos e, sobretudo, ao que se referia à mortalidade infantil. A percepção de que os cuidados com as gestantes e depois com os recém-nascidos implicariam em um investimento maior explica, assim, a opção de certos senhores por adquirir no mercado "escravos novos" para o aumento do seu plantel. ${ }^{6}$

Se houve casos em que as crianças escravizadas receberam um tratamento carinhoso, como referiram alguns viajantes estrangeiros, ou se outras poucas crescerem em companhia das crianças brancas, como afirmam alguns historiadores, também é verdade que muitas estiveram sujeitas aos caprichos, por vezes cruéis, dos filhos dos senhores. Como diz Maria de Fátima Rodrigues das Neves, era "a própria criança branca, 'proprietária' do menor escravo, que dava início ao martírio que o acompanharia durante quase toda a sua existência".?

Inerente ao cotidiano da escravidão, a violência infligida aos cativos é um fato exaustivamente apresentado pelos historiadores. Esta questão é muito mais sensibilizante quando diz respeito à crianças. A sua pouca idade e resistência física não comoveram muitos senhores de escravos: "Pode-se atribuir o rigor dos castigos físicos infligidos a pequenos cativos ao seu menor valor de mercado, ou seja, exposta a uma mortalidade elevada, a criança escrava não recebia, da parte do proprietário, um tratamento muito interessado em sua preservação. $\mathrm{E}$ talvez seja, precisamente esse, o motivo de tão elevada mortalidade das crianças escravas no seio da população escrava brasileira." ${ }^{8}$

Finalmente, muito cedo os pequenos escravos eram iseridos no mundo do trabalho. Como assinalou Mott, a "idade de cinco a seis anos parece encerrar uma fase na vida da criança escrava. A partir desta idade ela aparece desempenhando alguma atividade. [...] No meio rural, as mulheres e as crianças desempenham freqüentemente a mesma tarefa, como por exemplo descascar mandioca, descaroçar algodão e arrancar ervas daninhas". 9

\section{A criança escravizada no Rio Grande do Sul}

No Rio Grande do Sul, somente a partir da sistematização da produção do charque, em fins do século XVIII, e da caracterização da charqueada como principal atividade econômica, a utilização do braço 
escravo tornou-se diversificada e imprescindível. como diz Maestri, o "ciclo da charqueada inaugura a definitiva estruturação do escravismo como modo social de produção dominante de uma ampla região de nossos territórios"..$^{10}$

Nas charqueadas, para atender a um mercado em crescimento, 0 homem negro escravizado era utilizado até a exaustão. A violência, traduzida em castigos corporais, despontava como um meio de controle social a exemplo do que ocorria em outras regiôes do país.

O modo pelo qual o escravo foi submetido foi observado por Fernando Henrique Cardoso: "Nas charqueadas só era possível manter a disciplina no trabalho e o respeito aos senhores e à ordem escravocrata através do controle estreito do escravo e da violência institucionalizada que o capataz exercia em nome dos senhores. [...] De fato, existe documentação suficiente para comprovar o rigor existente no regime disciplinar nas charqueadas." 11

Por outro lado, o escravo no Rio Grande do Sul também rebelou-se contra sua condição, recorrendo ao suicídio, assassinando senhores e capatazes, fugindo e refugiando-se em quilombos.

Quanto às condições de vida das crianças escravas nada se sabe. 0 que se tem são informações esparsas, inexistindo estudos específicos. Fernando Henrique Cardoso, ao tratar da violência física contra os escravos, diz que "os excessos iam a ponto de permitir assassínios de crianças escravas". ${ }^{12}$

A imprensa, em 1881, noticiava a prática do infanticídio. Na ocasião fora "praticado por um senhor que, em vista da lei do ventre livre, acabara de atirar à rua, para morrer, um recém-nascido de escrava sua. Era a terceira vez que assim agia, tendo liquidado anteriormente outros dois filhos da mesma escrava". ${ }^{13}$

Também aqui os relatos dos viajantes referiam-se ao tratamento dispensado aos filhos dos cativos. Saint-Hilaire observou em uma das fazendas que: "Há sempre na sala um pequeno negro de 10 a 12 anos, cuja função é ir chamar os outros escravos, servir água e prestar pequenos serviços caseiros. Não conheço criatura mais infeliz que esta criança. Nunca se assenta, jamais sorri, em tempo algum brinca! Passa a vida tristemente encostado à parede e é freqüentemete maltratado pelo filho do dono. À noite chega-lhe o sono, e, quando não há ninguém na sala, cai 
de joelhos para poder dormir. Não é esta casa a única que usa este impiedoso sistema: ele é freqüente em outras." ${ }^{14}$

Uma outra atitude em relação aos filhos dos escravos foi indicada pela historiadora Margaret Bakos. Embora não tenha se detido na questão. Bakos dá pistas de ter sido comum também aqui a prática de se eliminar os recém-nascidos para que as mães fossem alugadas como amas-de-leite. ${ }^{15}$ Com efeito, muitas destas nutrizes negras foram contratadas pela Santa Casa de Misericórdia de Porto Aleg. para alimentarem as crianças abandonadas na Roda dos Expostos.

Embora em pequeno número, é possível que algumas das - rianças negras deixadas na Roda dos Expostos da Santa Casa fossem filhas de escravas. A partir de 1837, por imposição da Assembléia Legislativa Provincial, a Santa Casa assumiu a tarefa de recolher e cuidar de expostos, responsabilidade que até então coubera à Câmara Municipal. Desde então, a Misericórdia inaugura, no Rio Grande do Sul, o confinamento dos enjeitados e a institucionalização do abandono, tendo como princípio básico a construção de cidadãos úteis a si e à sociedade. ${ }^{17}$

Entre 1838 e 1880, foram recolhidas 1894 crianças, das quais 74 eram negras. Raramente se sabe se eram ou não filhas de mulheres escravas. O abandono de recém-nascidos negros pode ter sido maior, já que não foi feito o registro da cor da criança nos anos 1838 e 1839 . Em outros anos há omissão deste registro em alguns casos. No que foi possível averiguar, somente 40 crianças negras foram expostas antes da Lei do Ventre Livre. Após a Lei e até 1880 , somente 34 crianças. ${ }^{18}$

Por outro lado, 445 crianças abandonadas eram de cor parda e também é possível que muitas delas fossem filhas de escravas. ${ }^{19} \mathrm{De}$ qualquer modo, o abandono na Roda de Expostos de recém-nascidos negros e pardos pode ser atribuído, por ora, ao interesse do proprietário em alugar a escrava como ama-de-leite. Todavia, é preciso que, através de um estudo meticuloso, se conheça as razões de tão pequeno número de crianças negras abandonadas na Roda, no período acima referido.

\subsection{A mortalidade infantil entre a população escrava} no Rio Grande do Sul

Fundado em 23 de maio de 1850, o cemitério da Santa Casa de Misericórdia de Porto Alegre passou a sepultar a população da cidade e também da Província, sem restrição alguma sejam livres, libertos ou 
escravos. Ali eram sepultados os irmãos da Misericórdia, os membros de corporações religiosas, incluindo protestantes, os pobres e os indigentes.

Os escravos não eram sepultados dentro da área do cemitério mas em terreno próximo ao mesmo. ${ }^{20} \mathrm{o}$ enterro dos cativos não era gratuito custando, em 1848, mil réis, ao contrário dos marinheiros, dos pobres e dos praças da preta, que nada pagavam pela sua remoção e sepultu$\mathrm{ra.}^{21}$

Os Registros de Óbitos do Escravos sepultados no cemitério da Santa Casa tiveram início em 1850, estendendo-se até o final do escravismo. Felizmente foram preservados em sua totalidade e oferecem ao historiador a possibilidasde de reconstruir não só o quadro da mortalidade mas também a origem dos cativos, seu estado civil, suas idades, cores, atividades em que se empregavam e a quem pertenciam.

Para o estudo da mortalidade infantil foi feito o levantamento em quatro livros de registros, que abrangem o período de 1850 a 1872 . No caso presente delimitou-se o período da infância entre zero e quatorze anos de idade, conforme se procede atualmente. Não há um consenso entre os especialistas a este respeito e a fronteira que marca a passagem da infância para a adolescência é muito tênue. Algus pediatras admitem que ocorra aos 12 ou 13 anos e outros um pouco mais tarde.

A verificação da incidência dos óbitos foi distribuída nas seguintes categorias: faixa etária, sexo, cor, origem e causa das mortes. Como se trata de um tema que avança para o terreno da Medicina, buscamos a orientação de um profissional da área, no caso um pediatra, para que pudéssemos percorrer com mais segurança este caminho. ${ }^{22}$

No período em estudo (1850-1872) foram sepultados 4.511 escravos, dos quais 2.503 morreram entre 0 a 14 anos de idade, o que significa um percentual de $55,48 \%$ ! Considerando que foi um período de 23 anos, a média de sepultamentos ficou em torno de 108 crianças ao ano. 0 período de maior pico da mortalidade correspondeu aos anos de $1850-1855$, com $38 \%$ do total. Nestes cinco anos destacou-se 1851, com 181 crianças ou $19 \%$. O outro extremo - menor incidência - foi 1872 com apenas 29 crianças sepultadas ou 1,15\%. (Vide Gráfico 1) 
GRÁFICO 1

Demonstrativo do número de crianças entre a população escrava sepultada no cemitério da Santa Casa de Misericórdia de Porto Alegre 1850-1872

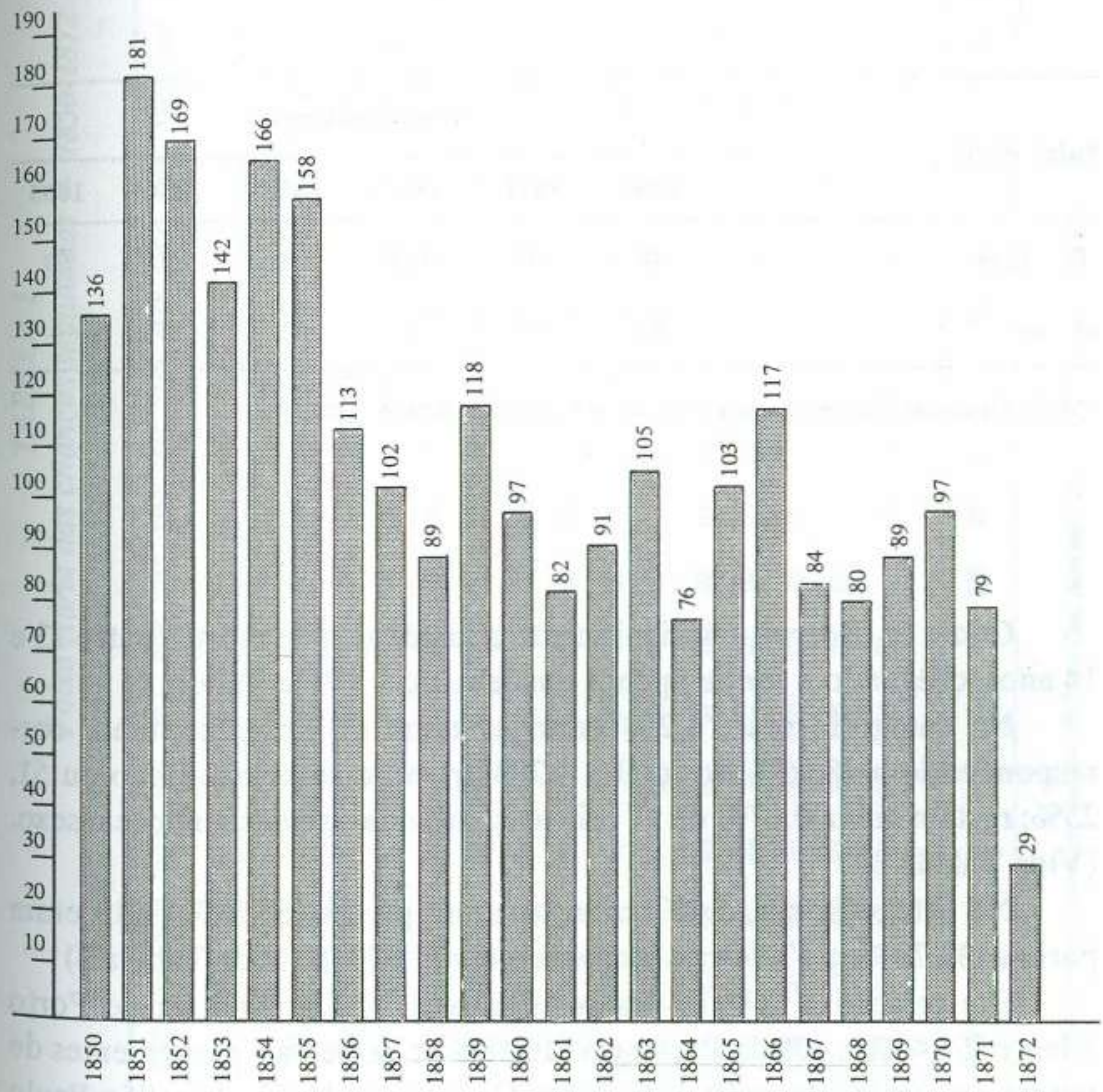

FONTE: Registros de Óbitos dos Escravos Sepultados no Cemitério da ISCMPA - CEDOP. 
$\mathrm{Na}$ categoria faixa etária constatou-se que $55,61 \%$ das crianças morreram entre 0 e 1 ano de idade, correspondendo a 1.392 óbitos. Em contrapartida, apenas 41 morreram entre 13 e 14 anos ou 1,63\%. A mortalidade na faixa etária de 0 a 1 ano foi sempre muito alta no período em estudo e, a título de exemplificação, vejamos o período de 1850 a 1855 que, como já foi dito, caracterizou-se por ser o de maior incidência de óbitos:

\begin{tabular}{lcccccc}
\hline & \multicolumn{7}{c}{$\mathrm{N}^{\circ}$ de 6́bitos/ano } \\
\cline { 2 - 7 } Faixa etária & $\mathbf{1 8 5 0}$ & $\mathbf{1 8 5 1}$ & $\mathbf{1 8 5 2}$ & $\mathbf{1 8 5 3}$ & $\mathbf{1 8 5 4}$ & $\mathbf{1 8 5 5}$ \\
\hline $0-1$ ano & 74 & 110 & 105 & 78 & 94 & 77 \\
$13-14$ & 01 & 05 & 01 & 03 & 02 & - \\
\hline
\end{tabular}

FONTE: Registros de Óbitos dos Escravos Sepultados no Cemitério da ISCMPA — CEDOP.

Como se observa, é insignificante a incidência de mortes entre $13 \mathrm{e}$ 14 anos, chegando a ser de apenas uma em 1855. (Vide Tabela 1)

$\mathrm{Na}$ categoria sexo, 1.203 crianças eram do sexo feminino, correspondendo a $48,06 \%$ do total e 1.283 eram do sexo masculino ou 51 , $25 \%$; restam ainda $0,67 \%$ ou 17 crianças, das quais se desconhece o sexo. (Vide Tabela 2)

$\mathrm{Na}$ categoria cor, 1.637 crianças eram pretas $(65,28 \%), 819$ eram pardas $(32,72 \%)$ e 47 desconhecemos a cor $(1,87 \%)$. (Vide Tabela 3 )

Em relação à origem destas crianças, 1.587 provinham de Porto Alegre (63,40\%), 405 da Província $(16,18 \%)$ e as demais provenientes de outras províncias do país: 3 de Santa Catarina (0,11\%), 2 de São Paulo $(0,07 \%), 7$ de Rio de Janeiro (0,27\%), 3 de Pernambuco (0,11\%), 1 de Goiás $(0,03 \%)$. Além destas, 21 provinham da África $(0,87 \%)$ e 473 crianças são de origem desconhecida (18,89\%). (Vide Tabela 4) 


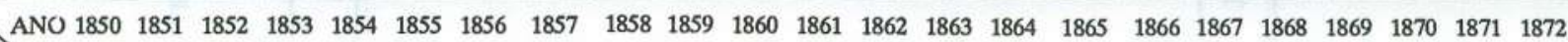
IDADE

\begin{tabular}{|c|c|c|c|c|c|c|c|c|c|c|c|c|c|c|c|c|c|c|c|c|c|c|c|}
\hline 0 a 1 & 74 & 110 & 105 & 78 & 95 & 77 & 63 & So & 40 & 58 & 47 & 51 & 48 & 54 & 39 & 63 & 64 & 50 & 54 & 54 & 60 & 50 & 08 \\
\hline 1 a 2 & 29 & 33 & 30 & 34 & 36 & 35 & 23 & 20 & 24 & 30 & 23 & 13 & 21 & 19 & 15 & 22 & 20 & 16 & 09 & 19 & 17 & 10 & 10 \\
\hline 2 a 3 & 08 & 08 & 10 & 06 & 10 & 08 & 07 & 07 & 06 & 04 & 06 & 01 & 09 & 08 & 03 & 08 & 07 & 04 & 01 & 06 & 07 & 03 & - \\
\hline 3 a 4 & 05 & 06 & 06 & 03 & 02 & 06 & 03 & 03 & 05 & 03 & 04 & 06 & - & 05 & 03 & - & 05 & - & 01 & 01 & 03 & 05 & 02 \\
\hline 4 a 5 & 02 & 04 & 02 & 03 & 02 & 07 & 04 & 02 & 03 & 05 & 03 & 02 & 01 & 05 & 03 & 01 & 02 & 04 & - & 01 & - & 01 & 01 \\
\hline 5 a 6 & 02 & 03 & 03 & 05 & 04 & 04 & - & 06 & - & 04 & 01 & 02 & - & 02 & - & 02 & 03 & 03 & 02 & - & 02 & - & 02 \\
\hline 6 a 7 & 01 & 03 & 02 & 01 & 03 & 02 & 03 & - & 04 & 06 & 03 & - & - & 04 & - & 02 & - & 03 & 01 & 02 & 01 & 03 & 01 \\
\hline 7 a 8 & 04 & 03 & 01 & 02 & 03 & 02 & - & 05 & 02 & 01 & 01 & - & 04 & 02 & 01 & - & 03 & - & 02 & - & 02 & - & 01 \\
\hline 8 a 9 & - & - & 01 & 03 & 01 & - & 02 & 01 & - & - & - & - & - & 02 & 02 & - & 01 & - & - & 03 & 01 & 01 & 01 \\
\hline 9 a 10 & 03 & 03 & 02 & 02 & 02 & 03 & 01 & 01 & 01 & 02 & 03 & 02 & 02 & 01 & 02 & 01 & - & 01 & 01 & 01 & 01 & 01 & - \\
\hline 10 a 11 & 03 & - & 04 & - & 01 & 03 & - & - & 01 & 02 & 03 & 01 & 02 & 02 & 01 & 01 & 03 & 01 & 02 & - & 02 & 02 & - \\
\hline 11 a 12 & 02 & - & 02 & 01 & 03 & 05 & 04 & 03 & 01 & 02 & 01 & 02 & 01 & 01 & 03 & - & 02 & 02 & 02 & 01 & 01 & - & - \\
\hline 12 a 13 & 02 & 02 & - & 01 & 02 & 04 & 02 & 03 & 01 & 01 & - & 01 & - & - & 02 & - & 03 & - & 01 & - & - & 01 & 01 \\
\hline 13 a 14 & 01 & 05 & 01 & 03 & 02 & 02 & 01 & 01 & 01 & - & 02 & 01 & 03 & - & 02 & 03 & 04 & - & 04 & 01 & - & 02 & 02 \\
\hline Total & 136 & 181 & 169 & 142 & 66 & 158 & 113 & 102 & 89 & 118 & 97 & 82 & 91 & 105 & 76 & 103 & 117 & 84 & 80 & 89 & 97 & 79 & 29 \\
\hline
\end{tabular}

FONTE: Registros de Óbitos dos Escravos Sepultados no Cemitério da Santa Casa de Misericordia de Porto Alegre - CEDOP. 


\section{TABELA 2}

Sexo das crianças sepultadas - 1850-1872

\begin{tabular}{lcccc}
\hline Ano & Meninas & Meninos & N/C & TOTAL \\
\hline 1850 & 60 & 72 & 04 & 136 \\
1851 & 78 & 103 & - & 181 \\
1852 & 81 & 86 & 02 & 169 \\
1853 & 72 & 69 & 01 & 142 \\
1854 & 73 & 93 & - & 166 \\
1855 & 71 & 86 & 01 & 158 \\
1856 & 52 & 61 & - & 113 \\
1857 & 59 & 43 & - & 102 \\
1858 & 48 & 41 & - & 89 \\
1859 & 56 & 61 & 01 & 118 \\
1860 & 46 & 50 & 01 & 97 \\
1861 & 38 & 43 & 01 & 91 \\
1862 & 46 & 45 & - & 105 \\
1863 & 52 & 53 & - & 76 \\
1864 & 41 & 35 & - & 103 \\
1865 & 54 & 49 & - & 84 \\
1866 & 55 & 62 & - & 80 \\
1867 & 40 & 43 & 01 & 89 \\
1868 & 43 & 46 & 01 & 79 \\
1869 & 46 & 43 & - & 29 \\
1870 & 46 & 48 & 02 & 02 \\
1871 & 47 & 11 & -503 \\
1872 & 37 & 1.283 & 17 & \\
\hline TOTAL & 18 & & & \\
\hline & & & & \\
\hline
\end{tabular}

FONTE: Registros de Óbitos dos Escravos Sepultados no Cemitério da Santa Casa de Misericórdia de Porto Alegre CEDOP. 
Notas para o estudo da...

TABELA 3

Cores das crianças sepultadas - 1850-1872

\begin{tabular}{lrccc}
\hline Ano & Pretos & Pardos & N/C & TOTAL \\
\hline 1850 & 93 & 37 & 06 & 136 \\
1851 & 127 & 47 & 07 & 181 \\
1852 & 132 & 37 & - & 169 \\
1853 & 106 & 34 & 02 & 142 \\
1854 & 113 & 53 & - & 166 \\
1855 & 109 & 47 & 02 & 158 \\
1856 & 76 & 37 & - & 113 \\
1857 & 75 & 26 & 01 & 102 \\
1858 & 36 & 14 & - & 99 \\
1859 & 104 & 50 & 03 & 118 \\
1860 & 70 & 26 & 01 & 97 \\
1861 & 52 & 26 & 04 & 82 \\
1862 & 56 & 34 & 01 & 91 \\
1863 & 67 & 36 & 02 & 105 \\
1864 & 42 & 34 & - & 76 \\
1865 & 58 & 45 & - & 103 \\
1866 & 60 & 54 & 03 & 117 \\
1867 & 42 & 36 & 06 & 84 \\
1868 & 51 & 27 & 02 & 80 \\
1869 & 48 & 39 & 02 & 89 \\
1870 & 58 & 36 & 03 & 97 \\
1871 & 45 & 32 & 02 & 79 \\
1872 & 17 & 12 & - & 29 \\
\hline TOTAL & 1.637 & 819 & 47 & 2.503 \\
\hline
\end{tabular}
FONTE: Registros de Óbitos dos Escravos Sepultados no Cemitério da Santa Casa de Misericórdia de Porto Alegre -
CEDOP. 


\section{TABELA 4}

Origem das crianças sepultadas - 1850-1872

\begin{tabular}{|c|c|c|c|c|c|c|c|c|c|c|c|}
\hline $\begin{array}{l}\text { LOCAL } \\
\text { ANO }\end{array}$ & IDADE & $\begin{array}{l}\text { Porto } \\
\text { Alegre }\end{array}$ & $\begin{array}{l}\text { Prov, de } \\
\text { S. Pedro }\end{array}$ & $\begin{array}{c}\text { Santa } \\
\text { Catarina }\end{array}$ & S. Paulo & $\begin{array}{l}\text { Rio de } \\
\text { Janeiro }\end{array}$ & $\begin{array}{l}\text { Pernam- } \\
\text { buco }\end{array}$ & Goiás & África & $\mathrm{n} / \mathrm{c}$ & TOTAL \\
\hline 1850 & & 48 & 05 & - & - & - & - & - & 01 & 82 & 136 \\
\hline 1851 & & 57 & 15 & - & - & - & 01 & - & 05 & 102 & 181 \\
\hline 1852 & 25 & 121 & 22 & - & - & - & - & - & 04 & 22 & 169 \\
\hline 1853 & If & 123 & 14 & - & 01 & - & - & - & 01 & 03 & 142 \\
\hline 1854 & & 138 & 07 & - & - & - & - & - & 01 & 20 & 166 \\
\hline 1855 & & 20 & 09 & - & - & 01 & - & - & 02 & 126 & 158 \\
\hline 1856 & & 79 & 16 & - & - & - & - & - & 01 & 17 & 113 \\
\hline 1857 & 924 & 68 & 21 & - & - & - & 01 & - & 01 & 11 & 102 \\
\hline 1858 & & 64 & 22 & - & - & - & 01 & - & 02 & - & 89 \\
\hline 1859 & & 65 & 47 & - & - & 01 & - & - & 01 & 04 & 118 \\
\hline 1860 & & 40 & 50 & 01 & - & - & - & - & 01 & 05 & 97 \\
\hline 1861 & & 47 & 26 & - & - & - & - & - & 01 & 08 & 82 \\
\hline 1862 & & 54 & 30 & - & - & 01 & - & - & - & 06 & 91 \\
\hline 1863 & & 72 & 24 & - & - & - & - & - & - & 09 & 105 \\
\hline 1864 & & 60 & 13 & - & - & - & - & - & - & 03 & 76 \\
\hline 1865 & & 82 & 12 & - & - & 01 & - & - & - & 08 & 103 \\
\hline 1866 & & 83 & 23 & - & 01 & 01 & - & - & - & 09 & 117 \\
\hline 1867 & & 60 & 13 & - & - & - & - & - & - & 11 & 84 \\
\hline 1868 & & 65 & 08 & 01 & - & - & - & 01 & - & 05 & 80 \\
\hline 1869 & & 76 & 05 & - & - & 01 & - & - & - & 07 & 89 \\
\hline 1870 & & 79 & 09 & - & - & 01 & - & - & - & 08 & 97 \\
\hline 1871 & & 64 & 08 & 01 & - & - & - & - & - & 06 & 79 \\
\hline 1872 & & 22 & 06 & - & - & - & - & - & - & 01 & 29 \\
\hline TOTAL & & 1587 & 405 & 03 & 02 & 07 & 03 & 01 & 21 & 473 & 2503 \\
\hline
\end{tabular}


A categoria mais difícil de ser analisada é a que trata das causas das mortes. Inicialmente pretendia-se tentar encontrar uma relação entre as causas das mortes e as condições de vida dos escravos tentativa que, aliás, não é nova. ${ }^{23}$ Contudo, devido à ausência de estudos sobre este aspecto do escravismo, como já apontamos, torna-se impossível enveredar para este terreno.

Um outro obstáculo se apresenta em relação a esta questão: segundo o dr. Pilla Grossi, é bastante difícil estabelecer um vínculo entre a causa da morte e o tipo de vida dos escravos porque não há informações suficientes para que se possa fazer uma avaliação satisfatória do quadro patológico. Em outras palavras, não se tem em mãos o prontuário médico das crianças - ele simplesmente não existia.

Além disso, muitas das causas mencionadas não são propriamete doenças mas sintomas. Finalmente, grande parte dos diagnósticos refletiam as precárias condições de higiene, o desconhecimento de regras alimentares adequadas, enfim as próprias condições sanitárias da época. Estes fatores, conjugados, afligiam a sociedade como um todo e, guardadas as devidas proporções, vale para o Rio Grande do Sul a observação que Stuart B. Schwartz fez em relação à sociedade baiana: "As condições de insalubridade, a subnutrição e a falta de assistência médica afetavam um grande segmento da população livre além dos escravos na Bahia, mas sem dúvida o cativeiro criava certas condições especiais de mortalidade." 24

Foi possível classificar os diagnósticos em diversas categorias, podendo igualmente apresentar a incidência das mesmas. São inúmeras as causas apontadas, daí a necessidade de agrupá-las seguindo os critérios da Classificação Internacional de Doenças. ${ }^{25}$

Infelizmente, por não dispormos do auxílio de um computador nos limitamos a apresentar apenas as causas e o número de casos em cada uma dela, tendo que abandonar a idéia inicial de relacionar causa/ sexo/faixa etária.

Feitas estas colocações, são as seguintes as causas das mortes das crianças filhas de escravos sepultadas entre 1850 e 1872 no Cemitério da Santa Casa de Misericórdia: 
TABELA 5

Repartição dos Óbitos por causas - População infantil escrava sepultada no Cemitério da Santa Casa de Misericórdia de Porto Alegre

1850-1872

\section{Categoria das Doenças}

$\mathrm{N}^{\circ}$ de Casos

TOTAL

I - Doenças do aparelho respiratório

Laringite

Bronquite

Pneumonia

Broncopneumonia

Enfisema

Asma

Pleurisia

04

Pneumotórax

01

Abcesso do pulmão

Congestão pulmonar

Pleuropneumonia

Coriza

01

Hidrotórax

02

Defluxăo

01

II - Doenças do aparelho digestivo

Úlceras (intestinal, escrofulosa e gangrenosa) $\quad 04$

Gastrite $\quad 18$

Hernia umbilical 01

Abcesso no fígado $\quad 02$

Constipação 02

Peritonite 08

Hepatite 24

Esplenite 01

Mesenterite $\quad 18$

Indigestão 03

Cólica intestinal 01

Gastro hepatite 25

Gastro entero colite 23

Gastro hepato enterites $\quad 05$

Hepato colite $\quad 01$

Dispepsia 01

Aftas 12 


\section{Categoria das Doenças}

III - Algumas afeções originadas

no período neonatal

Tétano neonatal

(mal de sete dias, tétano

umbilical, trismus, trismus

nacientivus, tétano)

Asfixia (asfixiada)

Hemorragia umbilical

(esvaimento de sangue

pelo umbigo)

02

05

Icterícia

33

Convulsőes

03

IV - Doeças do sistema nervoso

e dos órgãos do sentido

Meningite

Encefalite

Mielite

10

Apoplexia

18

V - Doenças do aparelho circulatório

Endocardite

Aneurisma

03

Hidropericardite

03

VI - Transtornos do desenvolvimento e da erupção dos dentes

Dentiçăo

VII - Doenças do aparelho geniturinário

Cistite

VIII - Complicações da gravidez,

do parto e do puerpério

Intra uterina

01

Eclampsia

06

Prematuridade

23

Natimortos 
IX - Anomalias congênitas

Espinha bífida 01

Lesão no coraçăo $\quad 05$

Afecção congênita do coração $\quad 01$

Hidrocefalia (hiđrocéfalo hidrocefalite) $\quad 16$

Hipertrofia do coração $\quad 04$

Atrofia do coraçăo $\quad 01$

Dilatação do coração $\quad 01$

$\mathbf{X}$ - Doenças da nutrição

Marasmo 06

Inanição $\quad 07$

Raquitismo 19

$\mathrm{XI}$ - Doenças do sangue

Anemias

XII - Lesões e envenenamento

Mordedura de aranha $\quad 01$

Queimadura (combustão) 05

Afogada (afogamento, afogado no poço de casa, asfixia por submersão) $\quad 05$

Suicídio 01

Homicídio por estrangulamento 01

Morto por sua mãe $\quad 01$

Pisadura 01

Tombo 01

Coice de cavalo $\quad 01$

Comoção cerebral $\quad 02$

XIII - Doenças da pele e do tecido celular subcutâneo

Hidropsia 15

XIV - Neoplasmas

Escrófulas $\quad 17$

Tumores (cancro, tumor) $\quad 05$

XV - Doenças infecciosas e parasitárias

Cólera morbus

Disenteria 
Categoria das Doenças

$N^{\circ}$ de Casos

TOTAL

XV - Doenças infecciosas e parasitárias

Colite

Enterite

68

Gastrenterite $\quad 120$

Diarréia 113

Verminose 48

Tuberculose pulmonar $\quad 66$

Tuberculose mesentérica $\quad 32$

Coqueluche 51

Escarlatina $\quad 20$

Erisipelas $\quad 06$

Tétano (trismus) $\quad 32$

Bexigas 33

Sarampo 27

Caxumba 01

Tifo 19

Sifilis $\quad 18$

Bouba 03

Crupe (garrotilho, angina diftérica, angina laríngea, angina membranosa, angina maligna)

Colerina

XVI - Causas mal definidas

de mortalidade e morbidade

Repentinamente

80

Sem assistência médica $\quad 43$

Asfixia 03

Caquexia 05

Debiloide 01

Ao nascer $\quad 93$

XVII - Sintomas, sinais e

afecçóes mal definidas

Consumpção mesentérica $\quad 01$

Hemorragia 03

Gastroentero encefalite $\quad 01$

Convulsões $\quad 145$

Cianose 01

Gangrenas $\quad 02$

Tosses 45

Catarros 19

Ascites 05

Hemorragia pulmonar $\quad 01$

Moléstia interna $\quad 06$ 


\begin{tabular}{|c|c|c|}
\hline Categoria das Doenças & Te Casos & TOTAL \\
\hline \multicolumn{3}{|l|}{$\begin{array}{l}\text { XVII - Sintomas, sinais e } \\
\text { afeç̧ões mal definidas }\end{array}$} \\
\hline Moléstia crônica & 01 & \\
\hline Enfermidade que trouxe do ventre materno & 01 & \\
\hline Lesåo & 04 & \\
\hline Cãibras no sangue & 02 & \\
\hline Inflamação & 12 & \\
\hline Atrofia & 24 & \\
\hline Afecção pulmonar & 03 & \\
\hline Moléstia aguda & 01 & \\
\hline Astenia & 02 & \\
\hline Cólica & 03 & \\
\hline Consumpção & 11 & \\
\hline Infecçăo & 01 & \\
\hline Dartros & 02 & \\
\hline Paralisia & 01 & \\
\hline Látea (crosta látea) & 03 & \\
\hline Hipertrofia & 07 & \\
\hline Afecção do peito & 01 & \\
\hline Erupção pubi & 01 & \\
\hline Petino & 01 & \\
\hline Ataques & 23 & \\
\hline Febres & 32 & \\
\hline Paralisia e alienação mental & 01 & \\
\hline Supressão exantemática & 01 & \\
\hline Metástase exantemática & 01 & \\
\hline Vômito pulmonar & 01 & \\
\hline Tireóide & 01 & \\
\hline Gastro & 06 & \\
\hline Gastrobronquite & 01 & \\
\hline Abcessos & 02 & \\
\hline Hipertrofia mesentérica & 05 & \\
\hline Mesenterite & 18 & \\
\hline Tabe mensetérica & 04 & \\
\hline Apostma (apostma na cabeça) & 05 & \\
\hline Anasarca & 06 & \\
\hline
\end{tabular}

XVIII - Não legíveis, ignoradas, não-especificadas*

Total

Causas especificadas

Causas não-especificadas

FONTE: Registros de Óbitos dos Escravos Sepultados no Cemitério da Santa Casa de Misericórdia de Porto Ale! (1950-1872) - CEDOP/ISCMPA. 
As doenças do aparelho respiratório, do aparelho digestivo, as moléstias ocorridas no período neonatal e as infecciosas e parasitárias, foram responsáveis pela maior parte dos óbitos.

Na primeira categoria - Doenças do aparelho respiratório constatou-se 222 óbitos. A bronquite e a pneumonia se destacam, com $71,17 \%$ do total. A bronquite contribuiu para a morte de 55 crianças entre 30 dias e 1 ano de vida e a pneumonia atingiu 36 crianças nesta faixa etária. Apenas 3 casos de bronquite foram verificados entre crianças do 0 aos 30 dias de vida.

Na segunda categoria - Doenças do aparelho digestivo - com 149 óbitos, as mais freqüentes foram as gastrites, as hepatites, a mesenterite, a gastro hepatite, o gastroenterocolite e as aftas. Juntas, são responsáveis por $80,53 \%$ do total deste grupo.

A gastrite matou 13 crianças entre 0 - 12 meses, sendo que destas 3 situavam-se na faixa etária de 0 a 30 dias. As hepatites levaram à morte 11 crianças na faixa 0 aos 12 meses, sendo que 1 delas entre 0 e 30 dias. A mesenterite matou 7 crianças entre 30 dias e 1 ano, a gastro hepatite matou 11 bebês entre 0 e 1 ano, dos quais 2 entre 0 e 30 dias. A gastroenterocolite foi responsável pela morte de 5 crianças entre 0 e 1 ano de vida. Finalmente, as aftas levaram à óbito 10 crianças na mesma faixa etária acima, sendo que 2 entre 0 e 30 dias.

A morte provocada por "aftas" chama a atenção. No entanto, consultando o Memorial Therapeutico de Chernoviz, constata-se que diagnosticava-se dois aspectos clínicos: poderia tratar-se de "lesão puramente local, não acompanhada de fenômenos gerais" ou "doença infecciosa, contagiosa e transmissível pelo leite", sendo "análoga à febre aftosa dos bovinos. Efetivamente esta forma encontra-se as mais das vezes nas crianças de leite e nos adultos submetidos ao regime lácteo".25

O mais curioso é que Chernoviz afirma que "a doença sara em uma semana. Só excepcionalmente é que aparecem complicações graves". Para obter-se a cura bastava suspender o leite contaminado, substituindoo por leite fervido; além disso deveria proceder-se a uma higienização da boca e purificação intestinal. ${ }^{26}$

Sendo assim, é possível que as crianças que morreram desta doença tenham sido vítimas do desconhecimento da origem do mal por parte dos pais e/ou proprietários. 
$\mathrm{Na}$ terceira categoria - Afecções originadas no período neonatal - responsável por 201 óbitos, destaca-se o tétano neonatal mais conhecido como mal-de-sete-dias, em $75,12 \%$ do total.

O mal-de-sete-dias foi uma das causas de morte mais freqüentes entre os recém-nascidos no Brasil. Schwartz indica a possibilidade, para o caso da sociedade colonial baiana, de que as atitudes relativas aos partos de recém-nascidos escravos, os quais eram feitos pelos próprios negros, poderiam ter contribuído para a incidência deste mal entre a população escrava baiana: "Após o nascimento [...], o cordão umbilical era cortado a uma boa distância do corpo e besuntado com óleo e pimenta, costume este que talvez contribuísse para a infecção do tétano o mortal mal-de-sete-dias" ${ }^{27}$

Para o contexto do Rio Grande do Sul podemos por ora simplesmente constatar a grande incidência de 'mal' também aqui.

Neste grupo ainda, estão as convulsões, responsáveis por $16,41 \%$ das mortes. Cumpre assinalar que foram registrados neste grupo apenas as convulsões de recém-nascidos, sendo que a morte por esta causa também atingiu outras faixas etárias.

$\mathrm{Na}$ quarta categoria - Doenças infecciosas e parasitárias - ocorreram 842 6bitos. A desinteria (110 casos), a gastrenterite (120 casos) e a diarréia (113 casos) são as principais.

Neste grupo situa-se também o cólera morbus que, no Rio Grande do Sul apresentou-se como surto epidêmico nos anos 1855 e 1867, sendo responsável, no caso presente, pela morte de 40 crianças. Consideramos este índice parcialmente já que há inúmeros registros de óbitos cuja causa mencionada foi o cólera morbus, sem que fosse mencionada a idade das pessoas. Sendo assim, é muito provável que o número de crianças fosse muito maior.

Algumas causas mencionadas foram classificadas na categoria Causas mal definidas de mortalidade e morbidade, responsáveis por 225 óbitos. Neste grupo chama atenção a morte por falta de assistência médica ( 43 casos) e a morte ao nascer ( 93 casos). No primeiro caso 35 crianças ou $81,39 \%$, situavam-se na faixa etária de $0 \mathrm{a} 1 \mathrm{ano}$. A morte por falta de assistência denota negligência embora não se saiba se por parte dos pais ou dos proprietários dos escravos.

A morta ao nascer pode ter inúmeras causas, inclusive a falta de assistência imediata ou debilidade extrema. Cumpre assinalar que 0 
termo é bastante vago, podendo estar ocultando as verdadeiras causas do 6 bito.

Um grande número de causas mencionadas foram agrupadas na categoria Sintomas, sinais e afecções mal definidas, totalizando 447 óbitos.

Retomando a questão do vínculo entre mortalidade e condições de vida dos escravos, há forte indícios desta possibilidade na população aqui tratada. Neste sentido estão as doenças da nutrição, com 7 casos de morte por inanição, 19 casos de raquitismo e 6 casos de marasmo.

Há ainda os casos evidentes - embora raros - de morte deliberadamente provocadas: estrangulamento (1 caso), degola (1 caso), "morto por sua mãe" (1 caso) e suicídio (1 caso). O estrangulamento ocorreu com uma criança entre 30 dias e 1 ano e o suicídio foi praticado por um menino de 12 anos de idade.

Finalmente, há 59 casos em que se desconhece a causa das mortes por não ter sido mencionada, por ter sido registrado "ignorada" ou por nāo ser legível o registro.

\section{Conclusões}

A partir do que foi exposto é possível tecer algumas consideraçōes. A criança escrava sepultada no Cemitério da Santa Casa de Misericórdia no período de 1850 a 1872 era predominantemente do sexo masculino, situava-se entre 0 e 1 ano de idade provinha da capital da província e era de cor preta.

A grande incidência de b́bitos nesta faixa etária evidencia a precariedade do atendimento a que estiveram submetidas as crianças nos seus primeiros 12 meses de vida, precariedade esta resultante, por um lado, das condições sanitárias da época e, por outro, das condições de existência da população escrava. Contudo, se é relativamente fácil inferir acerca da situação sanitária como fator de influência na mortalidade, atingindo também a população livre e branca, a busca de respostas nas condições de vida dos escravos exige primeiramente que se investigue profundamente este aspecto do escravismo do Rio Grande do Sul, Por ora, considera-se mais prudente mencionar esta questão hipoteticamente.

Finalmente, dentre as causas de morte definidas mais precisamente, as doenças infecciosas e parasitárias foram responsáveis pela maioria dos óbitos. 


\section{Notas}

1. MATTOSO, Kátia de Queirós. Ser Escravo no Brasil. São Paulo, Brasiliense, 1982. p.50-1.

2. Apud CONRAD, Robert Edgar. Tumbeiros. O Tráfico de Escravos para o Brasil. São Paulo, Brasiliense, 1985. p.51.

3. MAURO, Frédéric. Portugal, o Brasil e o Atlântico (1570-1670). Lisboa, Estampa, 1989. Vol. I. p.232.

4. MATTOSO. Op. cit. p.87.

5. MOTT, Maria Lúcia de Barros. "A Criança Escrava na Literatura de Viagens". Caderno de Pesquisa da Fundação Carlos Chagas. s/data. p.60.

6. MAESTRI, Mário. A Servidão Negra. Porto Alegre, Mercado Aberto, 1988. p.100-1.

7. NEVES, Maria de Fátima Rodrigues das. Os "leva-pancađas": Violência contra a Criança Escrava no Século XIX. 1989. p.6. [mimeo]

8. NEVES. Op. cit. p.12.

9. MOTT. Op. cit. p.61.

10. MAESTRI, Mário. "O Escravo Africano no Rio Grande đo Sul". In: DACANAL, José Hildebrando (Org.). RS: Economia e Política. Porto Alegre, Mercado Aberto, Série Documenta 2, 1979.

11. CARDOSO, Fernando Henrique. Capitalismo e Escravidão no Brasil Meridional. Rio de Janeiro, Paz e Terra, 1977. p.138.

12. Idem. p.139.

13. "A Voz do Escravo", 1² de maio de 1881. Apud CARDOSO. Op. cit. p.140.

14. SAINT-HILAIRE,A. Viagem ao Rio Grande do Sul (1820-1821). Trad. de Leoman Azevedo Pena, Rio de Janeiro, Ariel Editora, 1935. p.93.

15. BAKOS, Margaret M. Escravismo e Abolição. Porto Alegre, Mercado Aberto, Série Documenta 13, 1982. p.14.

16. GERTZE, Jurema M. Infância em Perigo. A Assistência às Crianças Abanđonadas em Porto Alegre (1837-1880). Dissertação de Mestrado, PUCRS, 1990. p.182-3.

17. Idem. p.57-64.

18. GERTZE. Op. cit. p.162-6.

19. Idem. p.168.

20. Regimento para o Cemitério da Cídade de Porto Alegre. Porto Alegre, Typographia de Claudio Dubreil, 1849. art. 5․ p.3. CEDOP/ISCMPA.

21. Idem. p.4.

22. Registramos aqui o nosso agradecimento à colaboraçăo do đr. Sérgio Pilla Grossi, médico pediatra, chefe do Berçário da Maternidade Mário Totta - Santa Casa de Misericórdia đe Porto Alegre.

23. SCHWARTZ, Stuart B. Segredos Internos. Engenhos e escravos na sociedade colonial 1550-1835. São Paulo, Companhia das Letras, 1988. p.302.

24. CID - Classificação Internacional de Doenças. Porto Alegre, SAGRA, s.d.

25. CHERNOVIZ, Pedro Luiz Napoleão. Memorial Therapeutico. s/localidade, s/editora, s/data. p.1438-9.

26. Idem.

27. SCHWARTZ. Op. cit. p.329.

\section{Fontes manuscritas}

Registros de Óbitos dos Escravos Sepultados no Cemitério da Santa Casa de Misericórdia de Porto Alegre - Livros 1 a 4 (1850-1872) - CEDOP/ISCMPA. 


\section{Fontes impressas}

Regimento para o Cemitério da Cidade de Porto Alegre. Porto Alegre, Typographia de Claudio Dubreil, 1849. CEDOP/ISCMPA.

CHERNOVIZ, Pedro Luiz Napoleão. Memorlal Therapeutico ou Indicação Abreviada dos Symptomas das Moléstlas e dos Meios Empregados no Tratamento d'Ellas. s/localidade, s/editora, s/data.

\section{Bibliografia citada}

BAKOS, Margaret M. Escravismo e Abolição. Porto Alegre, Mercado Aberto, Série Documenta 13, 1982.

CARDOSO, Fernando Henrique. Capitalismo e Escravidảo no Brasil Meridional. Rio de Janeiro, Paz e Terra, 1977.

CONRAD, Robert Edgar. Tumbeiros. O Tráfico de Escravos para o Brasil. São Paulo, Brasiliense, 1985.

GERTZE, Jurema M. Infância em Perigo: a assistência às crianças abandonadas em Porto Alegre (1837-1880). Dissertação de Mestrado, PUCRS, 1990.

MAESTRI, Mário. A Servidảo Negra. Porto Alegre, Mercado Aberto, 1988.

MATTOSO, Kátia de Queiróz. Ser Escravo no Brasil. São Paulo, Brasiliense, 1982.

MAURO, Frédéric. Portugal, o Brasil e o Atlântico. (1570-1670). Lisboa, Estampa, 1989. Vol. 1.

MOTT, Maria Lúcia de Barros. "A Criança Escrava na Literatura de Viagens". Caderno de Pesquisa da Fundação Carlos Chagas. s/data.

NEVES, Maria de Fátima Rodrigues das. Os "Leva-Pancađas": violencia contra a Criança Escrava no Século XIX. 1989. [mimeo]

SAINT-HILAIRE, A. Viagem ao Rio Grande do Sul (1820-1821). Trad. de Leomam Azevedo Pena, Rio de Janeiro, Ariel, 1935.

SCHWARTZ, Stuart B. Segredos Internos. Engenhos e Escravos na Sociedade Colonial 1550-1835. Săo Paulo, Companhia đas Letras, 1988.

CENTRO DE DOCUMENTAÇÃO E PESQUISA (CEDOP) DA

SANTA CASA DE MISERICÓRDIA DE PORTO ALEGRE

Rua Prof. Annes Dias, 285

90040 Porto Alegre - RS - Brasil

Fone (0512) 28-1566 - ramal 4000 